\title{
SOFT CLUSTERING DENGAN ALGORITMA FUZZY K-MEANS (STUDI KASUS : PENGELOMPOKAN DESA DI KOTA TIDORE KEPULAUAN)
}

\author{
Soft Clustering With Fuzzy K-Means Algorithm \\ (Case Study: Village Grouping in Kota Tidore Kepulauan) \\ Muhamad Budiman Johra* \\ BPS Provinsi Maluku Utara \\ Jl Stadion No 60, Ternate, 97717, Indonesia \\ Corresponding author e-mail:* muhamad.budiman@bps.go.id
}

\begin{abstract}
Abstrak
Mengembangkan wilayah untuk mengurangi kesenjangan dan menjamin pemerataan merupakan salah satu dari tujuh agenda Pembangunana RPJMN IV Tahun 2020-2024. Setiap wilayah tentunya memiliki potensi yang berbeda, baik potensi fisik maupun non-fisik. Perbedaan inilah yang menjadi dasar dalam pengelompokan desa sehingga pembangunan desa menjadi lebih terarah. Secara umum metode klaster dapat dibedakan menjadi dua kelompok yaitu hard clustering dan soft clustering. Pada hard clustering setiap objek dipetakan terhadap setiap kelompok. Metode yang populer pada kelompok hard clustering adalah Cluster K-Means. Sedangkan pada soft clustering objek tidak hanya dipetakan kedalam satu kelompok. Fuzzy K Means (FCM) merupakan salah satu metode dalam soft clustering, dimana Fuzzy K Means merupakan pengembangan dari Cluster K-Means. Cara kerja FCM adalah objek diberi probabilitas yang pada dasarnya menggambarkan kepemilikan objek ke dalam Cluster.
\end{abstract}

Kata Kunci : Cluster K-Means, Fuzzy K-Means

\begin{abstract}
Developing areas to reduce inequality and ensure equity is one of the seven development agenda of the RPJMN IV for 2020-2024. Each region certainly has different potential, both physical and non-physical potential. This difference is the basis for village grouping so that village development becomes more focused. In general, the cluster method can be divided into two groups, namely hard clustering and soft clustering. On hard clustering, each data is mapped to each group. The method that is popular in the hard clustering group is $k$ means. whereas in soft clusters, objects are not only mapped into one group. Fuzzy K Means is one of the methods in soft clusters, where fuzzy $k$ means is the development of $k$ means. The way the FCM works is that items are given a probability which basically describes the ownership of items into the cluster.
\end{abstract}

Keywords: Cluster K-Means, Fuzzy K-Means

Article info:

Submitted: $07^{\text {rd }}$ April 2020

How to cite this article:

M. B. Johra, "SOFT CLUSTERING DENGAN ALGORITMA FUZZY K-MEANS (STUDI KASUS : PENGELOMPOKAN DESA DI KOTA TIDORE KEPULAUAN)", BAREKENG: J. Il. Mat. \& Ter., vol. 15, no. 02, pp. 385-392, Jun. 2021. 


\section{PENDAHULUAN}

Pembangunan merupakan upaya untuk meningkatkan kesejahteraan masyarakat yang ditandai peningkatan standard hidup (standard of living). Pembangunan juga dimaksud untuk mengatasi berbagai masalah yang dihadapi masyarakat [1]. Pembangunan membutuhkan perencanaan yang baik. Pembangunan yang terarah akan menyampaikan maksud dan tujuan sesuai target yang ditentukan. Untuk itu perlu suatu road map dalam pembangunan. Sesuai amanat Undang-Undang Nomor 6 Tahun 2014, Pembangunan Desa adalah upaya peningkatan kualitas hidup dan kehidupan untuk sebesar-besarnya kesejahteraan masyarakat desa, dengan mendorong pembangunan desa-desa mandiri dan berkelanjutan yang memiliki ketahanan sosial, ekonomi, dan lingkungan. Kondisi desa yang demikian dapat mempersempit kesenjangan antara desa dan kota. Selain itu, membangun keterkaitan ekonomi antara desa dan kota melalui pembangunan kawasan perdesaan[2]. Kota Tidore Kepulauan diresmikan pada tanggal 31 Mei 2003 berdasarkan Undangundang No 1 Tahun 2013, dimana sebelumnya merupakan bagian wilayah Kabupaten Halmahera Tengah. Wilayah Kota Tidore Kepulauan berada di 2 wilayah pulau yaitu di Pulau Tidore dan Halmahera. Kota Tidore kepulauan terdiri dari 90 desa. Desa di Pulau Tidore lebih didominasi kelurahan, sedangkan di dataran Pulau Halmahera lebih dominan desa. Setiap wilayah tentunya memiliki karakteristik yang berbeda baik karakteristik fisik maupun karakteristik non fisik, sehingga perlu dilakukan pengelompokan baik secara wilayah maupun secara geografis dalam rangka percepatan pembangunan desa. Pengelompokkan desa penting dilakukan untuk memperkuat upaya pemerintah dalam memfasilitasi pembangunan sesuai dengan kriteria kelompok desa. Dalam penelitian ini desa akan dikelompokkan untuk menjadi tiga kelompok yaitu maju, berkembang, dan tertinggal. Pengelompokkan desa juga dilakukan oleh Sadewo et all (2019) juga melakukan pengelompokkan desa dalam klaster dengan menggunakan indikator keluarga pengguna listrik dan sumber penerangan jalan[3]. Penelitian serupa juga dilakukan oleh Ndraha et all (2018) yang menunjukkan beberapa faktor yang mendukung strategi pemberdayaan masyarakat dalam mengembangkan ekonomi lokal di Maluku Utara yaitu faktor pemetaan potensi daerah [4].

Atribut yang digunakan dalam pengelompokan desa diambil dari pendataan Potensi desa tahun 2020. Sampai saat ini, pendataan potensi desa merupakan satu satunya pendataan yang dilaksanakan Badan Pusat Statistik yang menyediakan data tematik berbasis kewilayahan yang dapat menggambarkan potensi yang terdapat dalam suatu wilayah [5]. Podes dilakukan juga pada tahun 2020.

\section{METODE PENELITIAN}

Penelitian ini dilakukan dengan menggunakan data sekunder yang berasal dari pendataan potensi desa Tahun 2020. Adapun tahapan dalam penelitian ini adalah

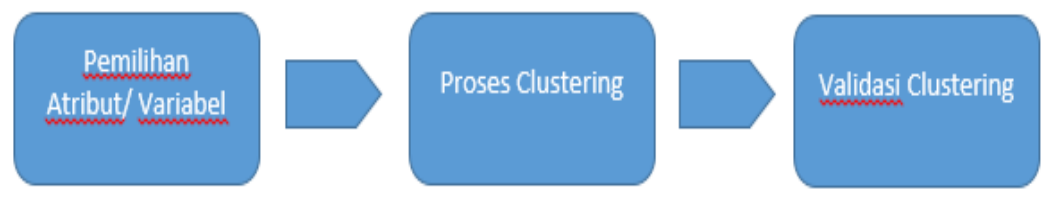

Gambar 1. Bagan Alir Penelitian

\subsection{Pemilihan Atribut/ Variabel Penelitian}

Sumber daya alam, sumber daya manusia merupakan faktor yang mendasar dalam proses pembangunan. Apabila faktor faktor ini berjalan seimbang tentunya pembangunan yang diharapkan akan berjalan dengan sangat baik, pembangunan yang baik mencerminkan kesejahteraan masyarakat yang baik pula [6]. Selain sumber daya alam dan sumber daya manusia, infrastruktur memegang peranan penting sebagai salah satu roda penggerak pertumbuhan ekonomi dan pembangunan. Keberadaan infrastruktur yang memadai sangat diperlukan. Sarana dan prasarana fisik, atau sering disebut dengan infrastruktur merupakan bagian yang sangat penting dalam sistem pelayanan masyarakat [7]. Pemilihan atribut dalam penelitian ini mencakup dimensi keluarga desa, dimensi infrastruktur, dan dimensi ekonomi yang mencakup 13 indikator. 


\subsection{Proses Clustering}

Clutering adalah proses membuat pengelompokan sehingga semua anggota dari setiap partisi mempunyai persamaan berdasarkan matriks tertentu. Analisis cluster atau analisis kelompok merupakan teknik analisa data yang bertujuan untuk mengelompokan individu atau objek ke dalam beberapa kelompok yang memiliki sifat berbeda antar kelompok[8]. Cluster yang baik adalah cluster yang mempunyai 1. homogenitas atau kesamaan yang tinggi antar anggota dalam satu cluster (within-cluster) dan 2. heterogenitas atau perbedaan yang tinggi antar cluster yang satu dengan cluster yang lainnya (betweencluster). Beberapa manfaat dari analisis cluster adalah: eksplorasi data peubah ganda, reduksi data, stratifikasi sampling, prediksi keadaan obyek. Secara umum metode cluster dapat dibedakan menjadi dua kelompok yaitu hard clustering dan soft clustering. Pada hard clustering setiap data dipetakan terhadap setiap kelompok. Metode yang populer pada kelompok hard clustering adalah K-Means. sedangkan pada soft clustering objek tidak hanya dipetakan kedalam satu kelompok. FCM merupakan salah satu metode dalam soft cluster, dimana FCM merupakan pengembangan dari K-Means. Cara kerja FCM adalah objek diberi probabilitas yang pada dasarnya menggambarkan kepemilikan objek ke dalam cluster atau dapat disimpulkan bahwa FCM merupakan versi fuzzy dari K-Means dengan beberapa modifikasi yang membedakannya dengan $K$-Means[9]. Beberapa penelitian yang dilakukan dengan menggunakan metode FCM oleh Kusuma Dwi, Hossen, Rahman, Sayeed, Samsuddin, dan Rokhani menyimpulkan bahwa Fuzzy $K$ means dapat menurunkan banyaknya iterasi, serta dapat memperoleh partisi data yang sangat tepat dan akurat[10]. Dalam proses pembentukan cluster, sudah terlebih dahulu ditentukan jumlah cluster sebanyak 3 cluster yang akan dikelompokkan menjadi desa maju, berkembang dan tertinggal, sehingga jumlah penanganan perkembangan desa menjadi lebih terarah dan menghindari jumlah cluster yang terlalu banyak. Tingkat keandalan dari cluster nantinya akan divalidasi oleh shilouette indeks.

\subsection{Fuzzy K Means (FCM)}

Metode Fuzzy C-Means (FCM) didasarkan pada teori logika fuzzy. Teori ini pertama kali diperkenalkan oleh Lothfi Zadeh(1965) dengan nama himpunan fuzzy (fuzzy set). Metode ini merupakan pengembangan dari metode partitioning data dengan pembobotan fuzzy. Keunggulan utama fuzzy clustering adalah dapat memberikan hasil pengelompokan bagi objek-objek yang tersebar tidak teratur, karena jika terdapat suatu data yang penyebaranya tidak teratur maka terdapat kemungkinan suatu titik data mempunyai sifat atau karakteristik dari cluster lain[11]. Dalam teori fuzzy, keanggotaan sebuah data tidak diberikan nilai secara tegas dengan nilai 1 (menjadi anggota) dan 0 (tidak menjadi anggota), melainkan dengan suatu nilai suatu nilai derajat keanggotaan yang jangkauan nilainya 0 sampai 1[12]. Semakin tinggi nilai keanggotaannya semakin objek tersebut masuk dalam cluster tersebut. Sebagai contoh jika umur dibawah 15 tahun termasuk cluster anak dan usia 65 tahun termasuk cluster tua, maka seseorang yang berumur 20 tahun dapat dikatakan akan masuk cluster 5 persen tua dan 95 persen masuk cluster muda. Metode FCM memiliki kemungkinan kegagalan untuk konvergen lebih kecil dari metode K-Means yang merupakan metode hard clustering [13] Dalam Fuzzy K Means setiap objek menjadi anggota pada setiap claster dengan derajat keanggotaan $u_{i j}$

Nilai derajat keanggotaan data $x_{i}$ pada klaster $c_{j}$, diformulasikan sebagai berkut:

$$
u_{i j}=\frac{D\left(x_{i}, c_{j}\right)^{\frac{-2}{w-1}}}{\sum_{i=1}^{k} D\left(x_{i}, c_{j}\right)^{\frac{-2}{w-1}}}
$$

Parameter $c_{j}$ adalah cluster ke-j, $D()$ adalah jarak antara data dengan centroid, sedangkan $w$ adalah parameter bobot pangkat (weighting exponent) yang diperkenalkan dalam Fuzzy K-Means. $W$ tidak memiliki nilai ketetapan, biasanya nilai $\mathrm{w}>1$ dan umumnya diberi nilai 2.

Nilai keanggotaan tersebut disimpan dalam matriks fuzzy pseudo-partition berukuran $N x k$, dimana baris merupakan data, sedangkan kolom adalah nilai keanggotaan pada tiap klaster. Bentuknya seperti dibawah ini:

$$
U=\left[\left[\begin{array}{ccc}
u_{11} x_{1} & \cdots & u_{1 k} x_{1} \\
\vdots & \ddots & \vdots \\
u_{n 1} x_{n} & \cdots & u_{n k} x_{n}
\end{array}\right]\right]
$$

Untuk menghitung centroid pada cluster $c_{i}$ pada fitur $\mathrm{j}$, digunakan persamaan berikut 


$$
C_{i j}=\frac{\sum_{i=1}^{N}\left(u_{i j}\right)^{W} x_{i j}}{\sum_{i=1}^{N}\left(u_{i j}\right)^{W}}
$$

Parameter $\mathrm{N}$ adalah jumlah data, $\mathrm{w}$ adalah bobot pangkat, dan $u_{i j}$ adalah nilai derajat keanggotaan data $x_{i}$ ke cluster $c_{j}$. Sementara fungsi objektif menggunakan persamaan berikut

$J=\sum_{i=1}^{N} \sum_{i=1}^{k}\left(u_{i j}\right)^{W} D\left(x_{i}, c_{j}\right)^{2}$

(3)

Secara prinsip, algoritma FCM memiliki banyak kesamaan dengan $K$-means.

\subsection{Validitas Cluster}

Terdapat beberapa metode dalam melakukan evaluasi dalam suatu cluster. Dalam penelitian ini metode evaluasi yang digunakan adalah metode silhouette coefficient. Metode ini merupakan metode validasi cluster yang menggabungkan metode cohesion dan Separation[14]. Untuk setiap objek $i$, hitung rata-rata jarak dari objek $i$ dengan seluruh objek yang berada dalam satu cluster. Akan didapatkan nilai ratarata yang disebut ai. Untuk setiap objek $i$, hitung rata-rata jarak dari objek $i$ dengan objek yang berada di cluster lainnya. Dari semua jarak rata-rata tersebut ambil nilai yang paling kecil. Nilai ini disebut $b i$.

Setelah itu maka untuk objek i memiliki nilai silhoutte coefisien:

$$
S I_{i}^{j}=\frac{b_{i}^{j}-a_{i}^{j}}{\max \left(a_{i}^{j} \cdot b_{i}^{j}\right)}
$$

Nilai $a_{i}^{j}$ mengukur seberapa data tidak mirip sebuah cluster yang diikutinya, nilai yang semakin kecil menunjukkan objek sudah berada pada cluster yang tepat. Nilai $b_{i}^{j}$ yang besar menandakan sebarapa tidak sesuainya objek terhadap cluster yang lain. Untuk nilai SI dari sebuah cluster didapatkan dengan menghitung rata-rata nilai SI semua data yang bergabung dalam cluster tersebut, seperti pada persamaan berikut:

$$
S I_{j}=\frac{1}{m_{j}} \sum_{1=1}^{m_{j}} S I_{i}^{j}
$$

Semntara nilai SI global didapatkan dengan menghitung nilai rata-rata SI dari semua cluster seperti pada persamaan berikut

$$
S I=\frac{1}{k} \sum_{j=1}^{k} S I_{j}
$$

Hasil perhitungan nilai silhoutte coeffisien dapat bervariasi antara -1 hingga 1. Berikut adalah kriteria nilai silhoutte index berdasarkan Kaufman dan Rousseeuw [15]:

Tabel 2. Klasifikasi Nilai Shilouette Indeks

\begin{tabular}{lc}
\hline Nilai SI & Kondisi Cluster \\
\hline $0,7<$ SI $<1$ & Strong Structure \\
\hline $0,5<$ SI $<0,7$ & Medium Structure \\
\hline $0,25<\mathrm{SI}<0,5$ & Weak Structure \\
\hline $\mathrm{SC}<0.25$ & No Structure Level \\
\hline
\end{tabular}

\section{HASIL DAN PEMBAHASAN}

Penelitian ini menggunakan aplikasi $\mathbf{R}$ sebagai aplikasi pengolahan data.

\subsection{Matriks Keanggotaan Cluster}

Soft Clustering berbeda dengan Hard Clustering dimana setiap item tidak hanya ditempatkan pada satu cluster tetapi diseluruh cluster. Berikut adalah matriks keanggotaan Cluster: 
Tabel 2. Matriks Keanggotaan Klaster

\begin{tabular}{cccc}
\hline Desa & Cluster 1 & Cluster 2 & Cluster 3 \\
\hline 1 & 0,8194 & 0,0396 & 0,1409 \\
\hline 2 & 0,8048 & 0,0439 & 0,1512 \\
\hline 3 & 0,9214 & 0,0182 & 0,8897 \\
\hline 4 & 0,0619 & 0,9757 & 0,0181 \\
\hline$\ldots$ & $\ldots$ & $\ldots$ & $\ldots$ \\
\hline 87 & 0,8538 & 0,0276 & 0,1186 \\
\hline 88 & 0,9597 & 0,0066 & 0,0337 \\
\hline 89 & 0,9787 & 0,0034 & 0,0179 \\
\hline 90 & 0,9608 & 0,0066 & 0,0326 \\
\hline
\end{tabular}

\subsection{Keanggotaan Cluster}

Berdasarkan hasil dari matriks keanggotaan maka dapat dibentuk keanggotaan klaster yang dapat dilihat pada Gambar 2.

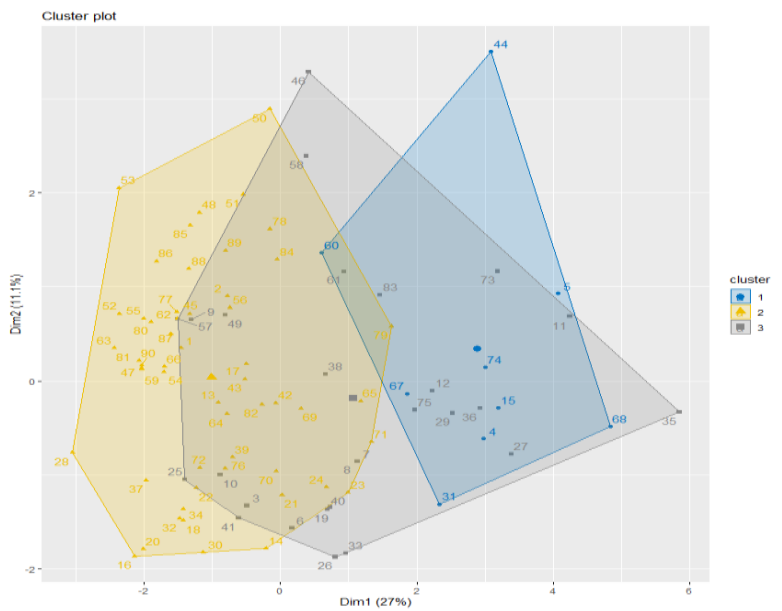

Gambar 2. Plot Klasifikasi Desa

Apabila dirinci perdesa maka keanggotaan tiap-tiap desa dapat dilihat pada Tabel 3, dibawah

Tabel 3. Keanggotaan Masing-masing Desa Hasil Clustering

\begin{tabular}{lclclc}
\hline Nama Desa & Cluster & Nama Desa & Cluster & Nama Desa & Cluster \\
\hline MAREKOFO & 1 & TOMAGOBA & 2 & LIFOFA & 3 \\
\hline MAREGAM & 1 & FOLARORA & 1 & NUKU & 1 \\
\hline TONGOWAI & 3 & GOTO & 3 & TAGALAYA & 1 \\
\hline GURABATI & 2 & TAMBULA & 1 & SOMAHODE & 1 \\
\hline TOMALOU & 2 & TUGUWAJI & 3 & AKEKOLANO & 1 \\
\hline TUGUIHA & 3 & DOWORA & 3 & OBA & 1 \\
\hline DOKIRI & 3 & KALAODI & 1 & SOFIFI & 2 \\
\hline TOLOA & 3 & MAFUTUTU & 3 & GURAPING & 2 \\
\hline BOBO & 3 & TOSA & 1 & KAIYASA & 1 \\
\hline AFA AFA & 3 & COBODOE & 3 & GAROJOU & 1 \\
\hline MAREKU & 3 & DOYADO & 3 & KUSU & 1 \\
\hline OME & 3 & JIKOCOBO & 1 & AMPERA & 1 \\
\hline JAYA & 1 & KUSU SINOPA & 1 & BUKIT DURIAN & 3 \\
\hline FOBAHARU & 1 & PAYAHE & 2 & GALALA & 2 \\
\hline
\end{tabular}




\begin{tabular}{lclclc}
\hline Nama Desa & Cluster & Nama Desa & Cluster & Nama Desa & Cluster \\
\hline RUM & 2 & TOSEHO & 1 & BALBAR & 3 \\
\hline MAITARA & 1 & GITA RAJA & 3 & GOSALE & 1 \\
\hline GUBU KUSUMA & 1 & WODA & 1 & TOGEME & 1 \\
\hline FOLONGO & 1 & KOSA & 1 & LOLA & 1 \\
\hline RUM BALIBUNGA & 3 & KOLI & 3 & AKELAMO & 1 \\
\hline MAITARA & 1 & BALE & 1 & AKEGURACI & 1 \\
SELATAN & 1 & TULUI & 1 & AKESAI & 1 \\
MAITARA & 1 & SIGELA YEF & 1 & AKETOBOLOLO & 1 \\
\hline MAITARA UTARA & 1 & TODAPA & 1 & AKEDOTILOU & 3 \\
\hline SELI & 1 & TALASI & 1 & AKETUBATU & 1 \\
\hline SOADARA & 3 & TALAGAMORI & 1 & TADUPI & 1 \\
\hline TOPO & 3 & UPT KOLI & 1 & YEHU & 1 \\
\hline SOA SIO & 3 & SELA & 3 & TAUNO & 1 \\
\hline GAMTUFKANGE & 1 & MALOFO & 3 & BERINGIN JAYA & 1 \\
\hline GURA-BUNGA & 3 & HAGER & 1 & FANAHA & 1 \\
\hline INDONESIANA & 1 & HAGER & 1 & SIOKONA & 1 \\
\hline TOPO TIGA & 2 & WAMA & 2 & & \\
\hline TOMAGOBA & & & &
\end{tabular}

Berdasarkan tabel diatas maka dapat terlihat bahwa untuk desa tipe 1 mayoritas merupakan desa yang berada di Pulau Halmahera, sedangkan untuk desa tipe 2 dan 3 berada di Pulau Tidore Kepulauan. Sehingga pembangunan di Wilayah Halmahera harus lebih diprioritaskan. Adapun pengelompokan cluster menjadi:

Cluster 1 : desa tipe 1 dimana merupakan desa dengan nilai atribut rendah atau dapat dikatakan desa tertinggal,

Cluster 2 : desa tipe 2 dimana merupakan desa dengan nilai atribut sedang atau dapat dikatakan desa berkembang,

Cluster 3 : desa tipe 2 dimana merupakan desa dengan nilai atribut tinggi atau dapat dikatakan desa maju

\subsection{Validitas Cluster}

Nilai Shilouette Indeks menunjukkan nilai 0,77 menunjukkan bahwa pengelompok desa dengan metode FCM sudah menunjukkan pengelompokkan yang baik (strong structure). Sehingga dapat diambil kesimpulan bahwa pengelompokkan desa untik Wilayah Kota Tidore Kepulauan sudah sesuai berdasarkan atribut yang telah ditetapkan.

\subsection{Profiling Cluster}

Berdasarkan Hasil FCM dapat dilakukan profiling cluster yang menjadi pembeda berdasarkan hasil final cluster prototypes

Cluster 1 : Desa dengan jumlah keluarga pengguna listrik pln rata rata 167 keluarga, rata-rata keluarga masih menggunakan bahan bakar kayu bakar untuk memasak, rata-rata keluarga masih menggunakan sumur sebagai sumber air minum, rata-rata jumlah smp sederajat 1 unit, rata-rata jumlah SMA sederajat 0,2 unit, rata-rata tidak memiliki puskesmas,

Cluster 2 : Desa dengan jumlah keluarga pengguna listrik pln rata rata 418 keluarga, rata-rata keluarga masih menggunakan bahan bakar minyak tanah untuk memasak, rata-rata keluarga masih menggunakan ledeng non meteran sebagai sumber air minum, rata-rata jumlah smp sederajat 1,5 unit, rata-rata jumlah SMA sederajat 0,7 unit, rata-rata jumlah puskesmas 0,1 unit. 
Cluster 3 : Desa dengan jumlah keluarga pengguna listrik pln rata rata 790 keluarga, rata-rata keluarga masih menggunakan bahan bakar minyak tanah untuk memasak, rata-rata keluarga masih menggunakan ledeng meteran sebagai sumber air minum, rata-rata jumlah smp sederajat 2,1 unit, rata-rata jumlah SMA sederajat 0,9 unit, rata-rata jumlah puskesmas 0,3 unit.

\section{KESIMPULAN}

Pengelompokan Desa menjadi tiga kelompok sudah menunjukkan hasil yang baik dengan melihat nilai shilouette indeks. Terdapat tiga kelompok desa yaitu desa maju dengan jumlah 6 desa, desa berkembang dengan 45 desa dan desa tertinggal sebanyak 39 desa. Dengan pengelompokkan desa diharapkan arah percepatan perkembangan pembangunan di Kota Tidore Kepulauan menjadi lebih terarah.

\section{DAFTAR PUSTAKA}

[1] D. A. Suseno, S. Sunarto, "Analisis Perencanaan Pembangunan Desa Berbasis Undang-Undang Desa No 6 Tahun 2014 di Kecamatan Gunung Pati Kota Semarang," Jurnal STIE Semarang, vol. 8, no. 2, pp. 122-137, Juni 2016.

[2] BPS, Pedoman Podes Desa, Jakarta: BPS, 2020.

[3] M. G. Sadewo, A. Eriza, A.P. Windarto, D. Ha.rtama, "Algoritma K-Means Dalam Mengelompokkan Desa/Kelurahan Menurut Keluarga Pengguna Listrik dan Sumber Penerangan Jalan Utama Berdasarkan Provinsi," Seminar Nasional Teknologi Komputer \& Sains (SAINTEKS), pp. 754-761, 26 Januari 2019, 2019.

[4] A. B Ndraha, D. P. Uang, "Strategi Pemberdayaan Masyarakat Desa Melalui Pengembangan Ekonomi Lokal di Kabupaten Halmahera Barat Provinsi Maluku," Jurnal Pembangunan dan Pemberdayaan Pemerintah, vol.3, no.2, pp. 137-149, November 2018.

[5] BPS Provinsi Maluku Utara, Statistik Potensi Desa Maluku Utara 2019, Ternate : BPS Provinsi Maluku Utara, 2020.

[6] M. Warouw, R. L. R. Paulus, P. Andrian, "Kajian Faktor-faktor dalam proses pembangunan desa di era otonomi daerah di kecamatan Sinonsayang," Jurnal Agro-Sosioekonomi, vol 11, no. 2A, pp. 13-20, Juli 2015.

[7] R. Indriani, “ Analisis Faktor-faktor yang Mempengaruhi Pelaksanaan Pembangunan Infrastruktur di Desa Sungai Cina Kabupaten Kepulauan Meranti Tahun 2016," Skripsi, Universitas Islam Negeri Sultan Syarif Kasim Riau, Pekanbaru, 2018.

[8] M. W. Talakua, Z. A. Leleury, A. W. Talluta," Analisis Cluster dengan Menggunakan Metode K-Means untuk Pengelompokkan Kabupaten/Kota di Provinsi Maluku Berdasarkan Indeks Pembangunan Manusia Tahun 2014," Barekeng: Jurnal Ilmu Matematika dan Terapan, vol. 11, no. 2, pp. 119-128, Desember 2017.

[9] E. Prasetyo, data mining konsep dan aplikasi menggunakan Matlab. Jogjakarta: Andi, 2003.

[10] J. Hossen, A. Rahman, S. Sayeed, K. Samsuddin, F.A. Rokhani, "A Modified Hybrid Fuzzy Clustering Algorithm for Data Partitions," Australian Journal of Basic and Applied Sciences, vol.5, no.8, pp. 674-681, Agustus 2011.

[11] W. Sanusi, A. Zaky, B.N. Afni, Analisis Fuzzy C-Means dan Penerapannya Dalam Pengelompokan Kabupaten/Kota di Provinsi Sulawesi Selatan Berdasarkan Faktor faktor Penyebab Gizi Buruk, UNM, 30 Mei 2018, [Online]. Tersedia : http://eprints.unm.ac.id/9027/ [Diakses : 24 Juli 2021].

[12] D.L. Rahakbauw, V.Y.U. Ilwaru, M.H. Hahury, "Implementasi Fuzzy C-Means Clustering dalam penentuan beasiswa," Barekeng: Jurnal Ilmu Matematika dan Terapan, vol. 11, no,1 pp. 1-11, Maret 2017.

[13] B. Muslimatun, "Perbandingan Metode K-Means dan Metode Fuzzy C Means (FCM) untuk Clustering Data", Skripsi, UIN Malang, Malang, 2011.

[14] R. Handoyo, R. Rumani, S.M. Nasution, "Perbandingan Metode Clustering Menggunakan Metode Single Lingkage dan KMeans pada pengelompokkan dokumen," JSM STMIK Mikroskil, vol.15, no.2, pp. 73-82, Oktober 2014.

[15] L. Kaufman, P.J. Rousseuw. Finding Groups in Data. New York: John Wiley\&Sons, 1990. 
